\title{
INTERNATIONAL CHARTER SUPPORT DURING MAJOR FLOOD DISASTERS IN INDIA
}

\author{
G. Srinivasa Rao*, C. M. Bhatt, P. G. Diwakar \\ National Remote Sensing Centre, Indian Space Research Organisation, India - (srinivasarao_g@nrsc.gov.in) \\ National Remote Sensing Centre, Indian Space Research Organisation, India - (bhatt_cm@nrsc.gov.in) \\ National Remote Sensing Centre, Indian Space Research Organisation, India - (pgdiwakar@nrsc.gov.in)
}

\section{Commission VI, WG VI/4}

KEY WORDS: International Charter, Disasters, Floods, India

\begin{abstract}
:
Earth observation (EO) satellites provide near real time, comprehensive, synoptic and multi-temporal coverage of inaccessible areas at frequent intervals, which is required support for a quick response and planning of emergency operations. Owing to their merits, satellite images have become an integral part of disaster management and are being extensively used globally for mapping, monitoring and damage assessment of extreme disaster events. During major disaster, information derived from satellite observation is not only highly useful, it may at times be indispensable because of the unfavourable weather conditions, collapse of communication systems and inaccessibility to the area. Satellite images help in identifying the location of the disaster, its severity and the extent. The International Charter 'Space and Major Disasters' has been the major sources of satellite data, in times of catastrophic disasters, due to availability of data from large number of sensors (with 15 organisations as signatories), which can be planned with the required temporal frequency and spectral range to cover a disaster event. During last three years, International Charter has been activated regularly, during major disasters in India. Satellite data from different sensors is obtained and was used for improving the frequency of observations, and extracting detailed information. This is used during floods in Assam (2012), floods in Uttarakhand (2013), cyclone Phailin (2013) and floods in Jammu and Kashmir (2014). The present paper discusses the role of International Charter in effective flood disaster management in India during recent past.
\end{abstract}

\section{INTRODUCTION}

Every year, millions of people worldwide are affected by natural disasters. Increased frequency and intensity of events, along with concerns about possible links to climate change, has put disasters high on the list of modern-day challenges.

Some major disasters across the globe during recent times are, Indain Ocean Tsunami (2004), Cyclone Nargis in Myanmar (2008), Haiti earthquake (2010), Earthquake and tsunami in Japan ( 2011), Flash Floods in India (2013), Typhoon Haiyan that devastated the Philippines (2013).

\section{INTERNATIONAL CHARTER SUPPORT}

\subsection{International Charter}

The idea of the Charter as a mechanism to supply satellite dataderived information in situations of crisis was introduced by the European (ESA) and the French (CNES) space agencies during the UNISPACE III conference held in 1999 (Bessis et al. 2003, 2004). Together with the Canadian Space Agency (CSA) in 2000, ESA and CNES made the foundation for Charter operations.

The advantage of the Charter is to cater to various needs during a major disaster, for quick coverage after the disaster, frequent coverage of the same area from multiple sensors, large area coverage from wide swath sensors, detailed information over the severely affected areas from very high resolution sensors, for and all weather capability from microwave sensors, etc.

The uniqueness of the Charter lies in a single point of contact and a coordinated approach to space supported disaster relief offered by the Charter members. Data acquisitions from multiple sensors, both passive and active, onboard the participating satellites are carried out with high planning priorities, and information products are delivered with short turnaround through pre-identified users (A. Mahamood et al, 2008).

At present, 15 organizations, which are satellite operators, are members of the Charter. These are Europe-ESA, France- CNES, Canada-CSA, US-NOAA, Argentina-CONAE, India-ISRO, Japan-JAXA, US-USGS, UK-UKSA/DMCii, China-CNSA, Germany-DLR, Korea-KARI, Brazil-INPE, EuropeEUMETSAT, Russia-ROSCOSMOS. The satellites from these organizations form a virtual constellation, comprising of both optical and microwave satellites.

The Charter is therefore benefiting from a growing number of organizations and satellites that increase the revisit frequency and the choice of sensor for spectral and spatial resolution.

Data from these sensors are processed, merged and interpreted in a variety of ways to extract the best possible information on the effects of a given disaster, as briefly described in this article.

\footnotetext{
* Corresponding author. This is useful to know for communication with the appropriate person in cases with more than one author.
} 
The Charter is a multi-satellite operational system to provide space-borne data on disasters that may have the potential of causing significant loss of life or property.

These data are viewed as an important complement to groundbased information, which is often difficult to generate because the infrastructures installed to generate the information are among the first victims of a disaster event.

Furthermore, satellites are the most effective means for synoptic viewing for disaster response on an emergency and priority basis. The Charter data are delivered to users on the ground with fast turnaround and at no cost. As can be understood from the foregoing account, the Charter covers only the response phase of a disaster, the later recovery and rehabilitation efforts are excluded. Only basic data (geo-referenced imagery) are provided, although any further value-adding and information extraction is generously sponsored by the individual Charter members. The satellite data are provided with due regard to the policies and procedures of the Charter and its member space agencies (Ahmed Mahmood, 2012)

So far the Charter was activated for about 440 major disasters across various countries in the world.

\section{MAJOR FLOODS IN INDIA}

India witnessed devastating floods and cyclones during 2012, 2013 \& 2014, during which ISRO has activated International Charter 'Space \& Major Disasters' for additional support for satellite imagery over affected areas.

It is a difficult task for any country to have good satellite coverage of a disaster event, with their own resources. However, with the help of other countries through International Charter frame work; there exists a constellation of satellites which can provide quick coverage of disaster affected areas, at best resolution.

\subsection{Assam Floods, 2012}

Assam (Figure-1) witnessed devastating floods in 2012 ever since 1998. As per official releases, all 27 districts were affected due to these floods. Lot of human loss, cattle loss, infrastructure loss was reported. Heavy damages to Kaziranga National Park and Majuli Island (world's largest river island) were reported.

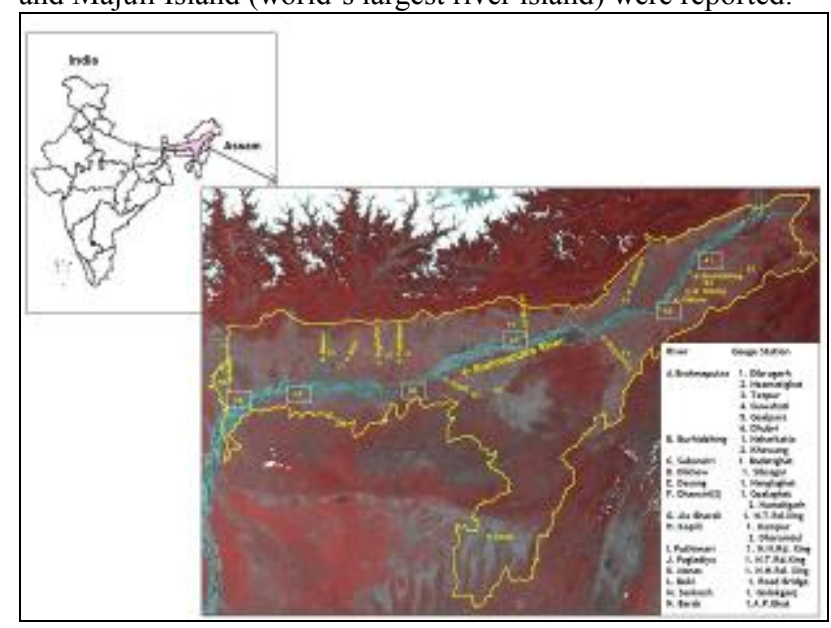

Figure 1. Location of Assam State
The severe floods in the Brahmaputra valley in Assam due to the rise in water levels of the Brahmaputra river and its associated tributaries probably resulted due to heavy incessant rainfall in the upper catchment areas of the Brahmaputra basin, caused by active monsoon conditions prevailing over the region during the third week of June. From the Central Water Commission (CWC) water level data it is observed that Brahmaputra river was flowing above danger level (DL) continuously for three days (27-29 June 2012) at six gauge stations located along the river and most of them had attained the peak flood level during this period. Peak water level attained during this event by the Brahmaputra river at most of the gauge stations was only a few centimetres below the previous high flood level (HFL) of 1998. At Dibrugarh, the first river gauge station on Brahmaputra River reached the peak flood level on 26 June 2012 whereas at Dhubri the last river gauge station on the Brahmaputra river attained the peak flood level on 30 June 2012.

\subsubsection{Satellite Based Monitoring of Floods}

NRSC, kept a close watch on the flood situation. All efforts are made to acquire the satellite data over flood affected areas in Assam. Emergency requests are placed for acquiring Resourcesat-1\&2, Cartosat-1\&2, Indian Microwave Satellites RISAT-1\&2 and also from Radarsat-1\&2 satellites. In addition, DSC has also activated International Charter "Space and Major Disasters" for frequent observations over the flood affected areas. Satellite data is received from CSA, USGS, DLR, JAXA.

\subsubsection{Overview of Flood Situation}

DSC has acquired and analysed satellite data of 27, $29 \& 30$ of June and 2 July 2012 and provided the overview of the flood situation to the concerned. Figure- 2 shows the flood affected areas in various districts of Assam State during 27-Jun to 02Jul, 2012. Major flood inundation was observed in the districts of Nowgong, Cachar, Marigaon, Sonitpur, Marigaon, Lakhimpur, Barpeta, Kamrup (R), Jorhat, Karimganj, Golaghat, Sibsagar, Dhemaji, Dibrugarh and Darrang districts.

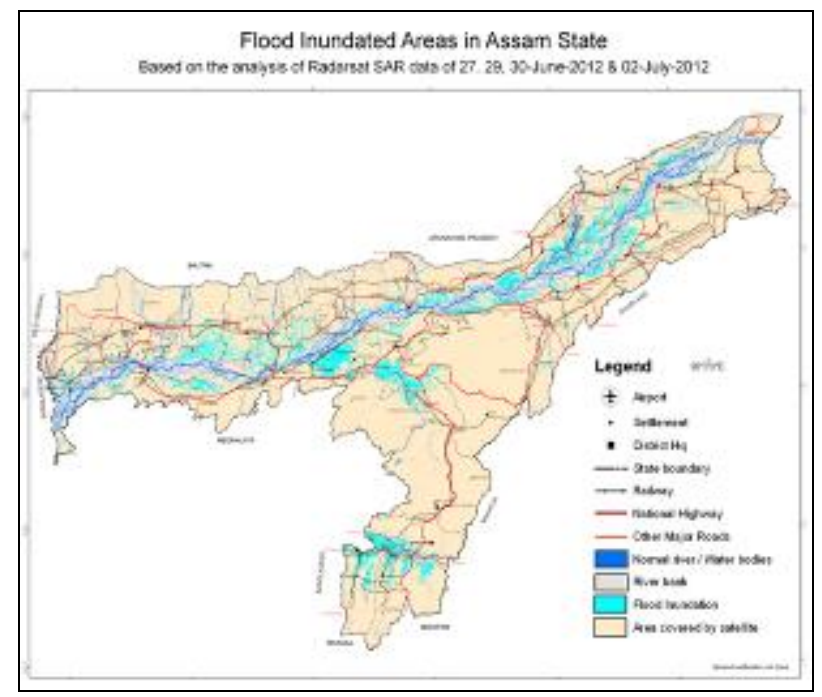

Figure 2. Overview of flood situation in Assam State

\subsubsection{Damage Assessment from High Resolution Data}


The activation of International Charter "Space and Major Disasters" helped in understanding the flood situation in detailed way and also provided close view on the damage to infrastructure particularly damages to roads, submerged railway tracks and embankment breaches.

\subsubsection{Affected Roads}

Due to the severity of the floods, roads were damaged at several places. About $426 \mathrm{~km}$ length of major roads in Assam state was observed to be affected by these floods as on July 02, 2012. Figure-3 shows the submerged roads near Kampur in part of Nowgong district as observed from GeoEye-1 data of July 05, 2012.

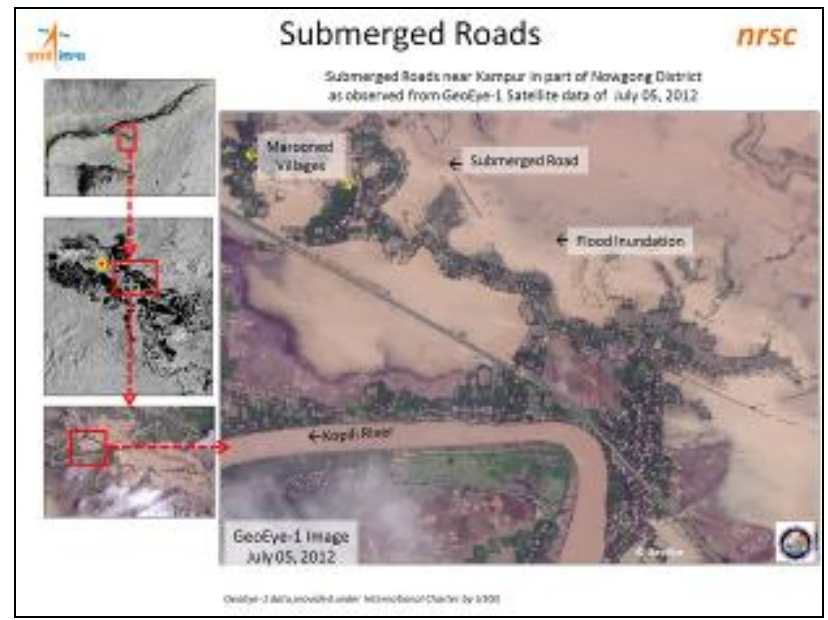

Figure 3. Submerged roads near Kampur, Nowgong district as observed from GeoEye-1 data of July 05, 2012.

3.1.5 Affected Railway Tracks: Significant damages to railway track due to these floods were reported. About $88 \mathrm{~km}$ length of railway track in Assam state was observed to be affected by these floods as on July 02, 2012. Figure-4 shows the affected railway track near Jamunamukh in part of Nowgong district as observed from GeoEye-1 data of July 05, 2012.

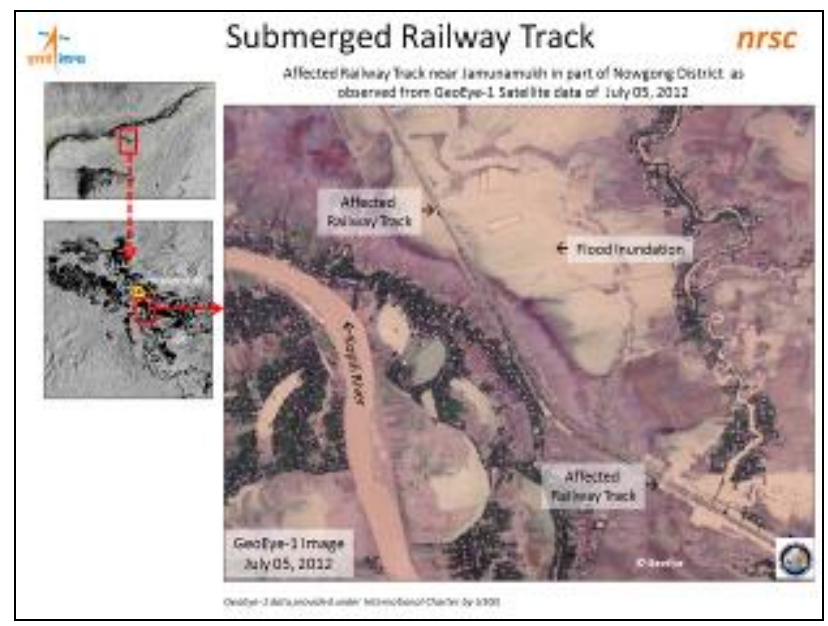

Figure 4. Affected railway track near Jamunamukh in part of Nowgong district as observed from GeoEye-1 data of July 05, 2012.
3.1.6 Embankment Breaches: As per the flood situation reports of ASDMA, several embankment breaches occurred during these floods. Fig-5 show the breaches in embankment of a tributary of Kopili River in Nowgong district as viewed by Terra SAR-X of 03-July-2012.

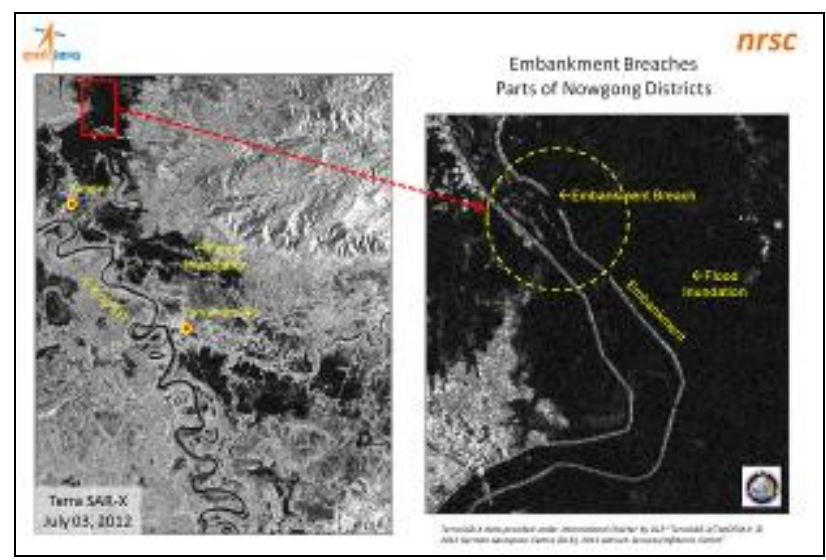

Figure 5. Embankment breach observed in part of Nowgong district July 03, 2012.

\subsection{Uttarakhand Floods, 2013}

Due to extreme weather conditions, heavy rainfall was reported in parts of Uttarakhand leading to flash floods and debris flow on 17-June-2013. The area in and around Kedarnath, Uttarakhand, witnessed a large scale damage to infrastructure, human lives and livestock. Extensive damages were also reported in places like Badrinath, Rudraprayag and Joshimath. Fig-6 shows the location map.

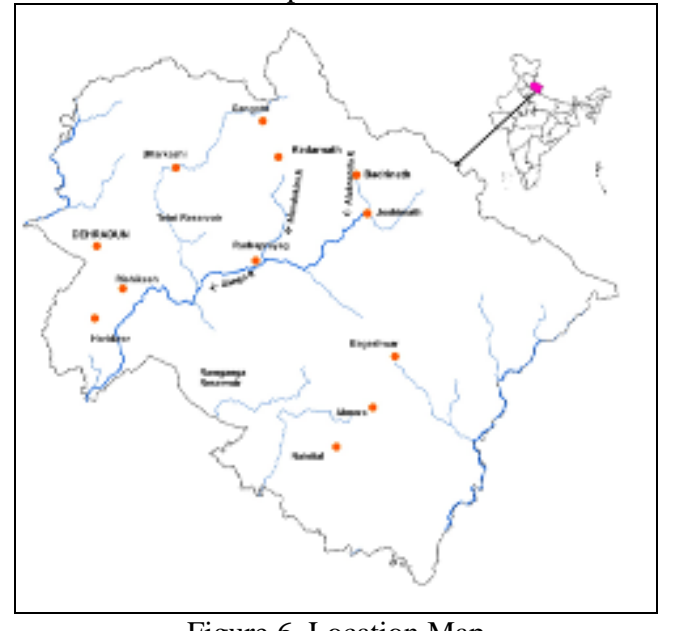

Figure 6. Location Map

\subsubsection{Satellite Based Support for Uttarakhand Floods}

NRSC has made extensive efforts to capture the impact of this event through satellite observation using Indian and foreign satellites. As this is a major disaster, International Charter was activated for acquiring more satellite observations over the affected area. High resolution satellite data from Worldview was received and used for damage assessment.

NRSC has provided the satellite based information on flood affected areas, landslides, damage to roads, damage to structures and damage to forest cover to various State and Central Govt 
Departments. Figure-7 shows the pre and post flood situation view of Kedarnath and surroundings.

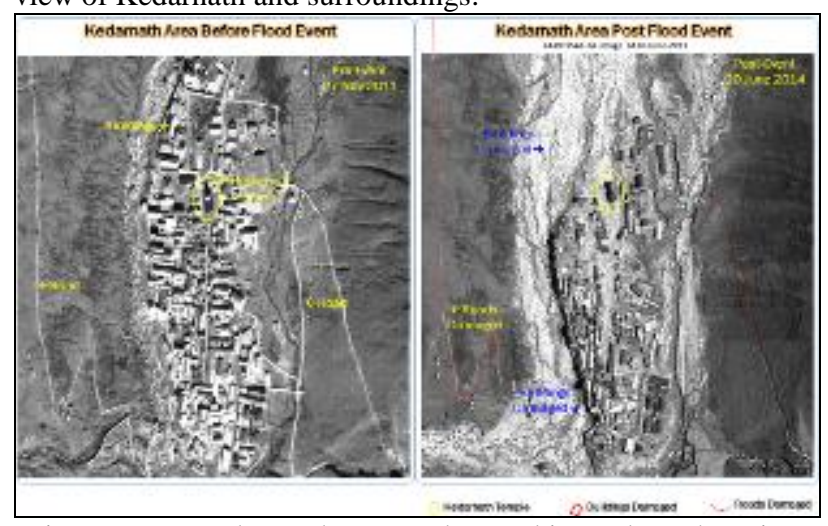

Figure 7. Pre and post damages observed in Kedarnath region.

All the products generated were uploaded to NRSC, Bhuvan and DSC websites for wider access to users. High resolution pre-event and post-event images acquired over Kedarnath were also uploaded on to ISRO's earth observation portal Bhuvan for better geovisualization of the information. These images and the information available on NRSC website has been globally accessed for understanding the event and documenting the sequence of events. NDEM-VPN network was also enabled for providing the information during this disaster event.

High resolution images available from Charter were very useful in identification and assessment of damages occurred to the infrastructure especially roads, bridges and hydro-electric projects. Figure- $8 \& 9$ show the damages observed to hydroelectric power projects, roads and bridges near Lambagrh village in Badrinath region

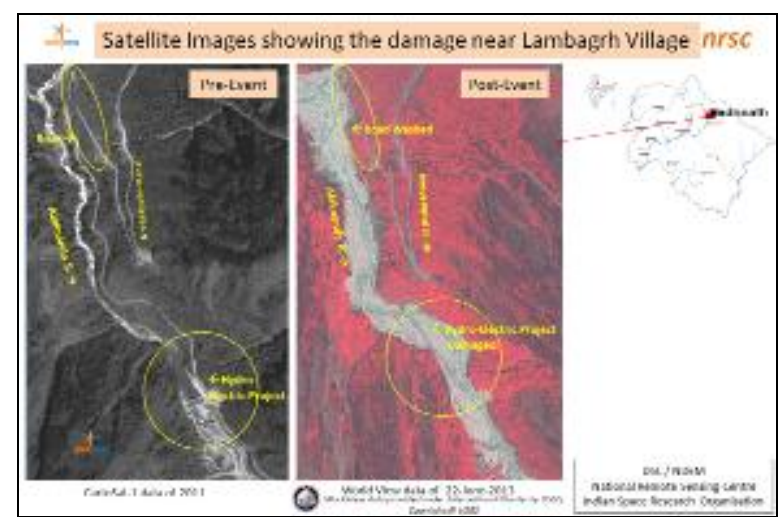

Figure 8. Damage to hydro electric project near Lambagrh village.

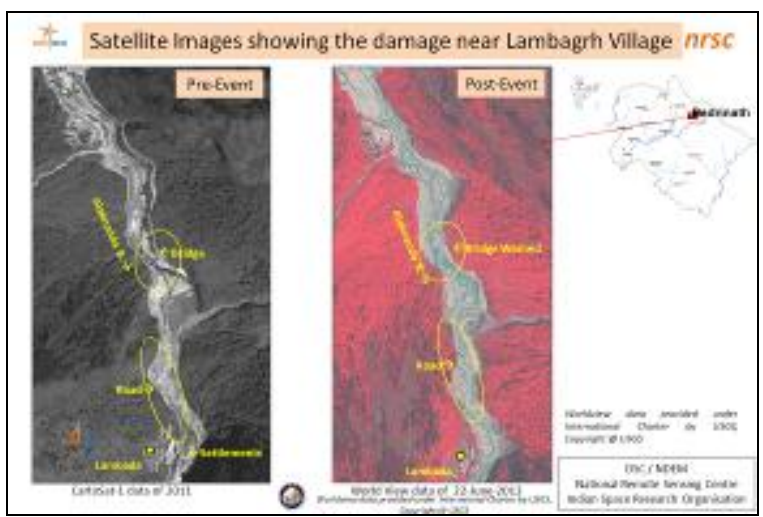

Figure 9. Damage to bridge and roads near Lambagrh village.

\subsection{Jammu \& Kashmir Floods, 2014}

Jammu \& Kashmir experienced the worst floods in the past 60 years during first week of September 2014 due to unprecedented and intense rains. The Jhelum River and its tributaries were in spate and caused havoc and huge damage in 5 districts Anantnag, Srinagar, Baramula, Pulwama and Badgam (Figure-10).

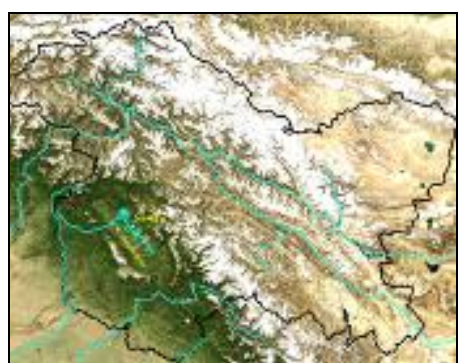

Figure 10. Location Map

\subsubsection{Satellite Based Monitoring of Srinagar Floods}

Emergency requests were placed for programming Indian Remote Sensing (IRS) as well as foreign satellites over Srinagar valley. International Charter was activated for acquiring more satellite data sets. Rapid flood mapping and monitoring was done on almost daily basis and the flood inundation information was disseminated in near real time to MHA, NDMA, Govt. of J\&K, National Security Council Secretariat and Defense Services. In addition, cumulative flood inundation maps and flood progression and recession maps were also disseminated. The flood products (Figure-11, $12 \& 13$ ) and flood layers were continuously published on Bhuvan and NDEM web portals. Value added satellite images showing the status of the flood situation were published on NRSC website.

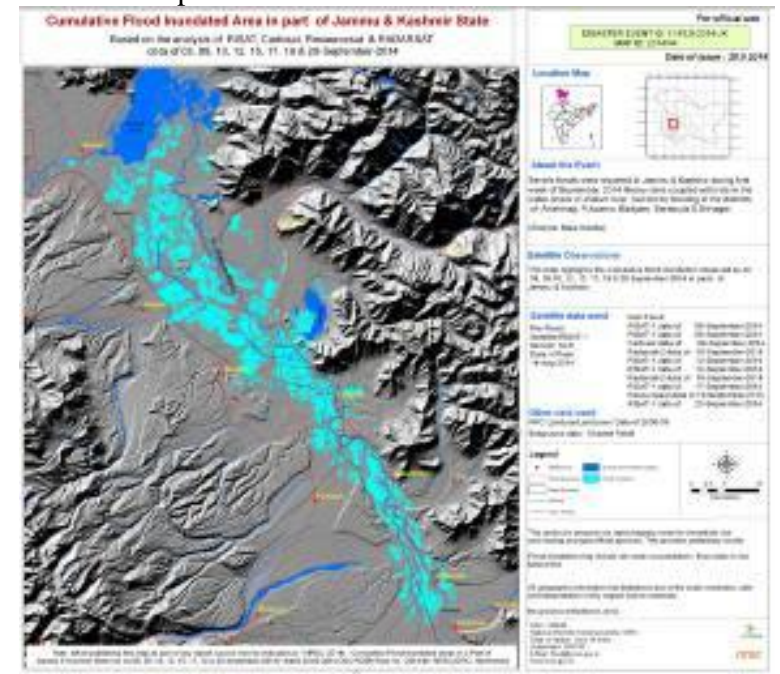

Figure 11. Cumulative flood iu8ndation observed during 8-20 Sep.2014 in Srinagar Valley

\subsubsection{Damage Assessment from High Resolution Data}

The activation of International Charter "Space and Major Disasters" for Jammu and Kashmir Floods has helped in understanding the flood situation and in identification of settlements, roads and railway network submerged. The high resolution satellite image annotated maps were prepared and 
provided to MHA, NDMA, and Govt of J\&K to help in relief and rescue operations.

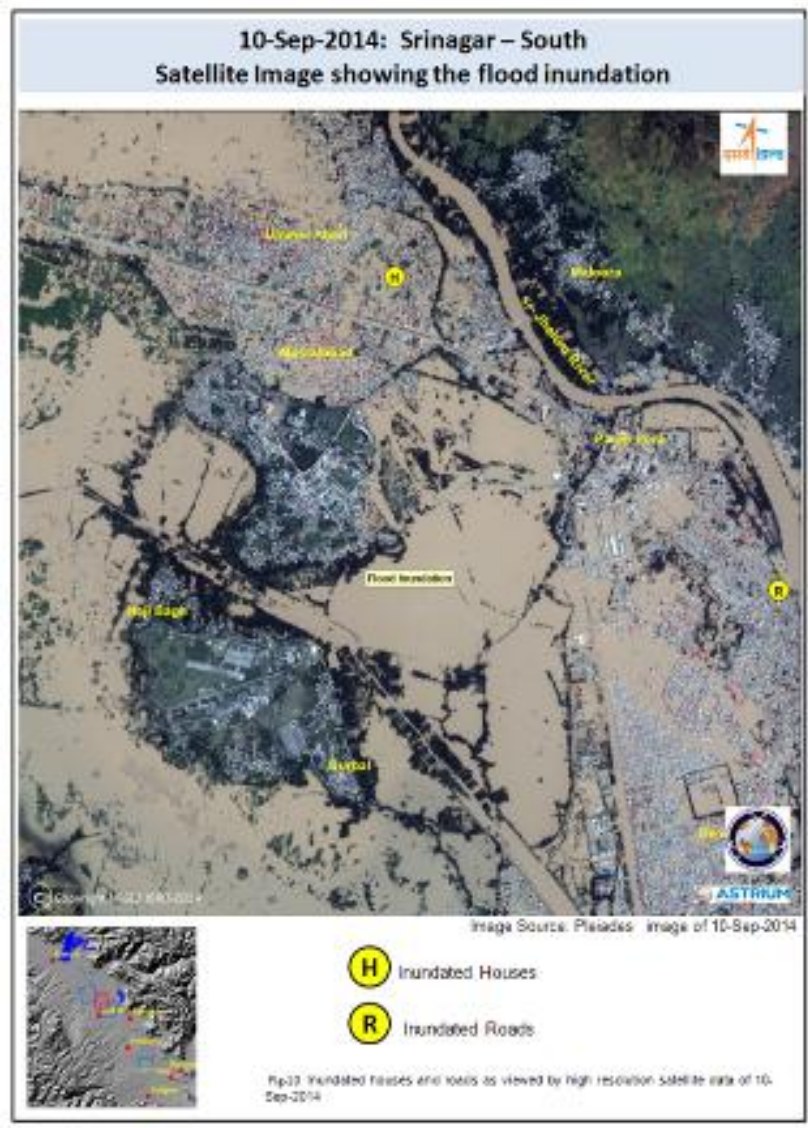

Figure 12. High resolution satellite image showing flood situation south of Srinagar.

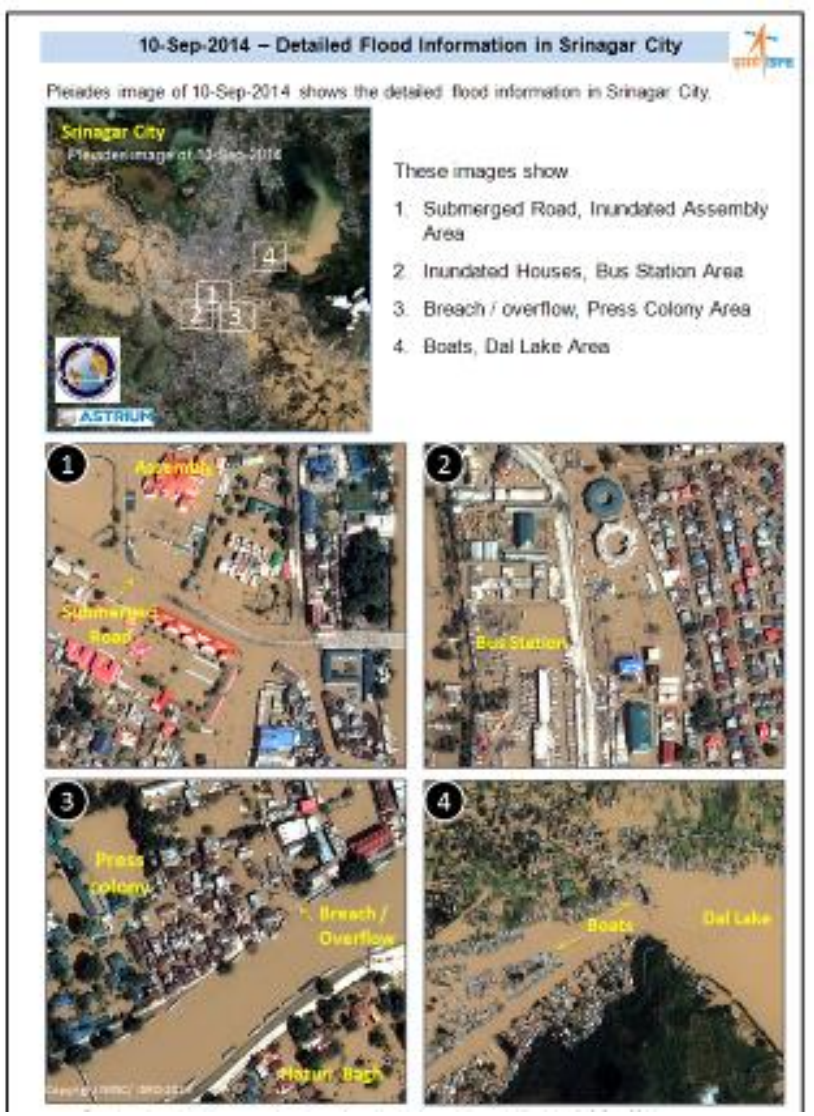

Figure 13. High resolution satellite image showing flood situation in parts of Srinagar city.

\section{CONCLUSIONS}

The high resolution satellite data received from Charter is very useful in time of crisis for understanding the disaster in detail and damage assessment of infrastructure. The activations of International Charter for the recent three flood disaster in Jammu \& Kashmir Floods, 2014, Assam Floods 2012 and Uttarakhand Floods 2010 has been very useful in providing information to the ground agencies for relief and rescue operations.

These three examples demonstrated the unique advantage of Charter. The floods in Assam (2012) calls for wide coverage, the floods in Uttarakhand (2013) calls for high resolution satellite data and Jammu \& Kashmir floods (2014) calls for high resolution data with frequent coverage. All these requirements were mostly addressed by Charter.

However, it is observed that some times, the same area is covered by two similar sensors. In the case of Jammu \& Kashmir floods, Srinagar city is covered by both Pleiades and Worldview-2 satellites. Instead, if these satellites cover different parts, that will be a major advantage. Hence, there is a need for optimal planning of these satellites for quick and systematic coverage of the affected area. With this type of unified approach, the effectiveness of Charter can be further enhanced.

\section{ACKNOWLEDGEMENTS}

The authors gratefully acknowledge the support and cooperation given by Director, National Remote Sensing Centre (NRSC), Hyderabad for carrying out the study. We also gratefully acknowledge the support and cooperation provided by the colleagues of DMSD, NRSC in carrying out the study.

\section{REFERENCES}

Ahmed Mahmood (2012) Monitoring disasters with a constellation of satellites -type examples from the International Charter 'Space and Major Disasters', Geocarto International, 27:2, 91-101

Bessis, J-L., Bequignon, J. and Mahmood, A., 2003. The International Charter "Space and major Disasters" initiative, Acta Astronautica, 54, pp.183-190.

Bessis, J-L., Bequignon, J. and Mahmood, A., 2004. Three typical examples of activation of the International Charter "Space and major Disasters" initiative, Advances in Space Research, 33 , pp.244-248.

Mahmood, A., Castan-Cubero, E., Platzeck, G. and Bequignon, J. 2008. South American perspective of the International Charter "Space and major Disasters", Advances in Geosciences, European Geosciences Union (EGU) 14, pp.13-20. 